\title{
CONCURSO DE PROYECTOS DE INVESTIGACIÓN 2008 SOCIEDAD CHILENA DE PEDIATRÍA
}

\section{Bases del concurso}

1. La Sociedad Chilena de Pediatría (SOCHI$\mathrm{PE})$ convoca al concurso de proyectos de investigación 2008, con la finalidad de estimular y apoyar las propuestas de los socios para la ejecución de investigaciones clínicas y epidemiológicas relacionadas con la salud infantil y del adolescente.

2. Se financiarán solamente proyectos de investigación originales, que conduzcan a la producción de nuevos conocimientos, mediante la aplicación del método científico. El monto de financiamiento para períodos de 2 años que la SOCHIPE contempla es de $\$ 10.000 .000$ (diez millones de pesos), con un máximo de \$2.000.000 (2 millones de pesos) por Proyecto. El número total de Proyectos aprobados dependerá de los presupuestos que contemplen los estudios presentados.

3. Podrán participar los socios con cuotas al día, y se dará preferencia a aquellos proyectos que no cuenten con otra fuente de financiamiento.

4. El investigador responsable y el coinvestigador deben ser socios de SOCHIPE.

5. Los participantes deberán presentar un proyecto de investigación en los formularios proporcionados por la Sociedad para este concurso.

6. La duración máxima del proyecto será dos años.

7. Todos los proyectos que contemplen la utilización de técnicas aplicadas a seres humanos, deberán incluir en su postulación un informe de un Comité de Ética acreditado.

8. Las propuestas seleccionadas obtendrán financiamiento para compra de material fungible, equipo menor, bibliografía, publicaciones y ayudas de viaje. No se contempla la asignación de recursos para honorarios de los investigadores, sin embargo, podrán destinarse parte de los fondos para cubrir costos de personal de apoyo. SOCHIPE se reserva el derecho de reducir las asignaciones presupuestarias solicitadas o rechazar un proyecto si su costo se estima excesivo para los objetivos propuestos.

9. El concurso acepta la adquisición de equipo menor. Al término del proyecto, los respectivos bienes de capital pasarán a ser propiedad de la unidad hospitalaria o académica a la cual pertenece el investigador responsable.

10. En el caso de la bibliografía adquirida (máximo 20\% del presupuesto), ésta deberá ser informada a SOCHIPE y ser entregada a la biblioteca de la unidad hospitalaria o académica respectiva al término del proyecto.

11. En razón de la naturaleza del presente Concurso, cuya finalidad es estimular la investigación a nivel nacional, los resultados del estudio deberán ser presentados en el Congreso Chileno de Pediatría y publicados en la Revista Chilena de Pediatría al término del proyecto, sin perjuicio de que el grupo investigador presente y publique el estudio en las instancias que considere convenientes, con la salvedad de no incurrir en publicación duplicada.

12.El concurso considerará el financiamiento total o parcial de publicaciones generadas como resultados del proyecto, utilizable del ítem bibliografía, con un tope de 10\%. Las publicaciones deberán consignar claramente el financiamiento otorgado por SOCHIPE.

13. El investigador responsable podrá utilizar en total hasta \$ 500.000 pesos durante la duración del proyecto, para viajes de presentación de resultados en Congresos Nacionales o Internacionales. Este monto permitirá cubrir parcial o totalmente pago de inscripción, pasaje y/o viático.

14.El concurso será fallado considerando el 
cumplimiento de los criterios contemplados en estas bases para lo cual ha constituido una Comisión de Investigación (CI) autónoma cuyas directrices, miembros y reglamentos se encuentran disponibles en la SOCHIPE. La resolución final del concurso corresponderá al Directorio de la Sociedad a partir de la puntuación final de los proyectos entregada por la CI.

15. Las evaluaciones considerarán principalmente los siguientes factores:

- Temas de morbilidad prevalente

- Calidad intrínseca de la investigación propuesta

- Relevancia de la investigación propuesta

- Antecedentes curriculares del investigador responsable y de los coinvestigadores

- Factibilidad de ejecución del proyecto en el periodo propuesto

- Incorporación de investigadores jóvenes al proyecto

- Adecuada justificación de los recursos solicitados

16. El investigador responsable deberá comprometerse a no ausentarse del país por más de 2 meses al año, comunicando a SOCHIPE cualquier situación que afecte el normal desarrollo del proyecto.

17. La entrega de los recursos del segundo año estará sujeta a la aprobación por la CI basado en el informe de avance y de las rendiciones económicas de la primera etapa. Al finalizar el proyecto, se deberá emi- tir un informe final.

18.SOCHIPE velará por el estricto cumplimiento en el uso de los recursos, por lo que cualquier modificación en el proyecto, ya sea en los equipos de trabajo, así como en su estructura presupuestaria deberá solicitar la aprobación previa. En este último caso, se aceptará un margen de variación de hasta un $5 \%$ en los porcentajes señalados, que no requerirán aprobación previa.

19. Cualquier otro aspecto no contemplado en estas bases, así como el incumplimiento de alguno de los párrafos ya señalados, habilita a la CI para aplicar su propio criterio como resolución.

20. La postulación se realiza a través del formulario proporcionado por la Sociedad, el que deberá ser presentado en 1 original, 2 copias en papel y un ejemplar electrónico.

21. Plazo para presentación de proyectos: vence el 30 Mayo 2008 hasta las 16:00 hrs, en la secretaría de SOCHIPE, Eduardo Castillo Velasco 1838, Ñuñoa, Santiago, para ser resueltos hasta el 31 de julio de 2008.

22. Los formularios estarán disponibles a contar del 11 de enero de 2008 en la sede de la Sociedad, o electrónicamente en http://www. sochipe.cl (concurso proyectos de investigación). Mayor información solicitarla al 2379757 ó 2371598; por email a contacto@ sochipe.cl.

\section{Comisión de Investigación. Sociedad Chilena de Pediatría}

